\title{
Tegaserod in the treatment of constipation-predominant irritable bowel syndrome. Do the risks outweigh the benefits?
}

\author{
Peter Wood
}

Received: 13 September 2011 / Accepted: 15 September 2011 /Published online: 4 October 2011

(C) Springer-Verlag 2011

\section{Editorial}

Irritable bowel syndrome (IBS) is a common disorder affecting up to $20 \%$ of the population in the USA (Johanson 2004). IBS is considered a functional bowel disorder resulting in abdominal pain and bloating, constipation and/or diarrhoea. Women are affected twice as frequently as men, generally in the $30-50$ year age group. Costs to society either directly (medical and diagnostic) or indirectly (time off work) were estimated to be approximately US $\$ 4$ billion per year for all functional bowel disorders in 2004 (American Gastroenterological Association (2011) website). Hence, this is a significant medical problem and a large therapeutic market.

Medical therapies to date have been varied and often symptomatic. Antispasmodics, antidiarrhoeals, laxatives, dietary modification, antidepressants and simple analgesics have all been utilised. None of these agents show what would be considered to be a good (level 1) evidence of efficacy (Johanson 2004; Enck et al. 2010).

The current concept of pathogenesis in IBD suggests a dysregulation between central nervous (CNS) and enteric nervous system (ENS) control. Intrinsic bowel functions such as motility and secretory functions are determined by the ENS with modification by the CNS. The neurotransmitter involved in many of these sites is serotonin (5-hydroxytryptamine, 5HT). Hence, manipulation of transmitter levels would be expected to change symptomatology. 5-HT3 increases gut

\footnotetext{
P. Wood $(\triangle)$

Pathology Queensland, Princess Alexandra Hospital

and University of Queensland, Australia,

Ipswich Road,

Woolloongabba, Queensland, Australia

e-mail: Peter_Wood@health.qld.gov.au
}

secretion, motility and sensation. 5-HT4 receptor agonists have been shown to increase peristaltic activity in animal models (Grider et al. 1998).

These pre-clinical findings led to the development of two potential treatments for IBS, alosetron (a 5-HT3 receptor antagonist) and tegaserod (a selective 5-HT4 receptor agonist). Tegaserod is in a novel class of drugs (aminoguanidine indoles) designed to be similar in structure to serotonin and to act selectively at 5-HT4 receptors in the GI tract. Tegaserod appears to be effective when assessed by a symptom score in two large, randomised, placebo-controlled trials (Novick et al. 2002; Muller-Lissner et al. 2001).

The adverse events most frequently recorded with Tegaserod are diarrhoea and headache occurring at approximately $10 \%$ and $15 \%$ of patients treated respectively (Johanson 2004; Muller-Lissner et al. 2001; Novick et al. 2002; Schoenfeld 2004). The severity of these events is usually mild.

Long-term safety data (up to 12 months of treatment) suggest that diarrhoea $(10.1 \%)$, headache $(8.3 \%)$, abdominal pain $(7.4 \%)$ and flatulence $(5.5 \%)$ remain the most common problems (Tougas et al. 2002).

ECG data from 2,516 patients with IBS treated with 4 $12 \mathrm{mg}$ of Tegaserod per day suggest that no significant electrocardiographic changes occur (Morganroth et al. 2002).

Tegaserod was approved in the USA in 2002 for treatment of constipation-predominant IBS in women and extended in 2004 to include both men and women up to the age of 65 years. It was denied approval in the EU and subsequently removed from the US market in March 2007 (Food and Drug Administration 2011; http://www.fda.gov/ Drugs/DrugSafety/PostmarketDrugSafetyInformationfor PatientsandProviders/DrugSafetyInformationforHeathcare Professionals/PublicHealthAdvisories/UCM051284) when findings (from 29 trials and reported to the FDA by the 
manufacturer, Novartis) suggested an increased risk of serious adverse cardiovascular effects (angina, myocardial infarction and cerebrovascular events). The frequency of these events was very small, occurring in 13 of 11,614 $(0.1 \%)$ patients treated with tegaserod compared with 1 of 7,031 placebo-treated patients $(0.01 \%)$ (see FDA hyperlinks referenced). However, the risk was felt to outweigh the benefit in most patients (although access was still available for "emergency" use in selected patients). The mechanism of these adverse events is unclear, and speculation has been on platelet aggregatory effects or coronary artery occlusive changes. Higgins et al., in this edition, have tried to evaluate a possible mechanism for these events by investigating the effect of tegaserod on platelet aggregation and coronary artery tone in an in vitro model.

Platelet function testing is commonly used to investigate bleeding problems in patients. They are able to detect abnormalities in platelet surface glycoproteins (e.g. Glanzmann's thrombasthenia) and also the effect of anti-platelet therapy (de Gaetano and Cerletti 2007). There are now even a variety of point-of-care instruments that can be used to monitor platelet inhibition (Price 2010).

However, platelet function testing has not been utilised clinically to predict a prothrombotic effect. In disorders where a prothrombotic tendency is well recognised (e.g. myeloproliferative disorders such as essential thrombocythaemia), platelet function testing has not been able to demonstrate consistent changes to predict this predilection (Bermejo et al. 2004). Hence, laboratory testing of platelet activation may be a poor indicator of clinical thrombotic sequelae even if it is demonstrated (Serebruany et al. 2010).

Higgins et al. in this issue have evaluated platelet aggregation in the presence and absence of tegaserod to determine whether enhanced platelet reactivity can be elicited on drug exposure. The assumption would then be that increased platelet aggregation is the cause of the apparent increased incidence of arterial thrombotic events. Platelet activation and aggregation is certainly important in both myocardial infarction and cerebrovascular accident as demonstrated by the marked efficacy of anti-platelet therapy in reducing these events.

Platelets in this study are collected from normal donors. Platelets in vivo may have already been activated by a variety of disease processes and hence might be more or less susceptible to the effects of tegaserod. These in vitro studies might then underestimate in vivo effects.

Similarly, in vitro studies of vascular tone on isolated coronary arteries probably do not reflect the complexities of real life. However, they are probably a reasonable and realistic model to utilise.

The study does not consider the effects on the endothelium and various biological mediators such as von Willebrand's factor, endothelial microparticles and even smooth muscle stem cells (to name but a few) that are almost certainly involved in arterial thrombosis (Mause et al. 2010).

Overall, IBS is a common disorder with a significant impact both symptomatically and economically. Effective therapy is important but must be safe given the low mortality of IBS. The risk of major cardiovascular events is small with tegaserod $(0.1 \%)$ and probably cumulatively related. Many patients may be prepared to accept these risks, certainly those patients with significant morbidity who derive clear benefit from treatment.

This small laboratory study cannot prove that tegaserod does not cause a significant clinical problem but may perhaps suggest other mechanisms by which the adverse events may arise.

Over the next few years, there will be newer agents competing for this large market (e.g. prucalopride, Camilleri et al. 2008, and lubiprostone, Schey and Rao 2011), and they will be scrutinised carefully for these and other adverse events. An understanding of the frequency and mechanism of these events may serve to reassure patients and regulators to allow access to a potentially beneficial group of drugs.

\section{References}

American Gastroenterological Association (2011) The burden of gastrointestinal diseases. American Gastroenterological Association, 2011, Bethesda, MD. Available at http://www.gastro.org/ education-meetings/online-education/niddk-burden-of-digestivediseases-in-the-united-states-educational-slides (link to "costs of digestive diseases"). Accessed 7 Sep 2011)

Bermejo E, Alberto MF, Meschengieser SS, Lazzari MA (2004) Assessment of platelet activation in myeloproliferative disorders with complementary techniques. Blood Coagul Fibrinolysis 15:235-240

Camilleri M, Kerstens R, Rykx A, Vandeplassche L (2008) A placebocontrolled trial of prucalopride for severe chronic constipation. $\mathrm{N}$ Engl J Med 358:2344-2354

de Gaetano G, Cerletti C (2007) Platelet function, antiplatelet therapy and clinical outcomes: to test or not to test? J Thromb Haemost 5:1835-1838

Enck P, Junne F, Klosterhalfen S, Zipfel S, Martens U (2010) Therapy options in irritable bowel syndrome. Eur J Gastroenterol Hepatol 2010(22):1402-1411

Food and Drug Administration (2011) FDA announces discontinued marketing of GI drug, Zelnorm, for safety reasons. Food and Drug Administration, Bethesda (MD). Available at http://www. fda.gov/NewsEvents/Newsroom/PressAnnouncements/2007/ ucm108879.htm. Accessed 4 July 2011

Grider JR, Foxx-Orenstein AE, Jin JG (1998) 5-Hydroxytryptamine4 receptor agonists initiate the peristaltic reflex in human, rat, and guinea pig intestine. Gastroenterology 115:370-380

Serebruany VL, El Mouelhi M, Pfannkuche H, Rose K, Marro M, Angiolillo D (2010) Investigations on 5-HT4 receptor expression and effects of tegaserod on human platelet aggregation in vitro. Am J Ther 17:543-552

Johanson JF (2004) Options for patients with irritable bowel syndrome: contrasting traditional and novel serotonergic therapies. Neurogastroenterol Motil 16:701-711 
Mause SF, Weber C, Sampol J, Dignat-George F (2010) New horizons in vascular biology and thrombosis: highlights from EMVBM 2009. Thromb Haemost 104:421-423

Morganroth J, Ruegg PC, Dunger-Baldauf C, Appel-Dingemanse S, Bliesath H, Lefkowitz M (2002) Tegaserod, a 5hydroxytryptamine type 4 receptor partial agonist, is devoid of electrocardiographic effects. Am J Gastroenterol 97:2321-2327

Muller-Lissner SA, Fumagalli I, Bardhan KD et al (2001) Tegaserod, a 5-HT4receptor partial agonist, relieves symptoms in irritable bowel syndrome patients with abdominal pain, bloating and constipation. Aliment Pharmacol Ther 15:1655-1666

Novick J, Miner P, Krause R et al (2002) A randomized, double blind, placebo-controlled trial of tegaserod in female patients suffering from irritable bowel syndrome with constipation. Aliment Pharmacol Ther 16:1877-1888

Price J (2010) The evidence base for platelet function testing in patients undergoing percutaneous coronary intervention. Circ Cardiovasc Interv 3:277-283

Schey R, Rao SSC (2011) Lubiprostone for the treatment of adults with constipation and irritable bowel syndrome. Dig Dis Sci $56: 1619-1625$

Schoenfeld P (2004) Review article: the safety profile of tegaserod. Aliment Pharmacol Ther 20(suppl 7):25-30

Tougas G, Snape WJ, Otten MH et al (2002) Long-term safety of tegaserod in patients with constipation-predominant irritable bowel syndrome. Aliment Pharmacol Ther 16:1701-1708 